A collaboration between the JAOA and the American Association of Colleges of Osteopathic Medicine (AACOM) to recruit, peer review, publish, and distribute research and other scholarly articles related to osteopathic medical education.

\title{
JAOA/AACOM
}

\section{An Education in Osteopathic Ultrasonography (AEIOU) Program: One Institution's Approach to Advancing an Ultrasonography Curriculum}

Tami Hendriksz, DO; Zachary Markman, DO; Abraham Pera, DO

From the Touro University

College of Osteopathic Medicine-CA (TUCOM) in Vallejo (Drs Hendriksz and Pera) and the Department of

Psychiatry and Behavioral

Medicine at the Medical

College of Wisconsin in Milwaukee (Dr Markman). Dr Markman was a student at TUCOM at the time that this article was written and submitted.

Financial Disclosures: None reported.

Support: None reported.

Address correspondence to

Tami Hendriksz, DO, Clinical Education Department, TUCOM, 1310 Club Dr, Vallejo, CA 94592-

1187.

Email: tami.hendriksz@tu.edu

Submitted

December 20, 2017;

revision received

April 17, 2018;

accepted

May 17, 2018.
Advances in ultrasonography (US) have allowed this technology to play an increasingly important role in numerous fields of medicine. It is important that medical schools incorporate this broadly applicable tool into their curricula. Touro University College of Osteopathic Medicine-CA has implemented a progressive US curriculum that is intended to complement osteopathic education, keep pace with medical advances, and arm future physicians with the most advanced skills and tools to practice medicine. In this article, the authors highlight the importance of US training in medical education and demonstrate the relative ease, cost-effectiveness, and direct benefit to students of implementing such a curriculum. The authors discuss the specifics of the US curriculum in osteopathic undergraduate medical education and describe how a staged rollout helped the college address the need for funding, faculty, and facilities. Plans for continued expansion, the successful and effective use of peer educators, the outcomes measured from this project, and avenues for further study are also discussed.

J Am Osteopath Assoc. 2018;118(11):746-752

doi:10.7556/jaoa.2018.160

Keywords: clinical medicine, internal medicine, medical education, osteopathic medicine, ultrasonography

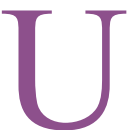

ltrasonography (US) has been a diagnostic tool for decades used by traditional imaging specialists. ${ }^{1}$ The development of portable and handheld equipment has led to the use of this technology by diagnosticians at the hospital bedside and in the office at the point of care. ${ }^{2}$ An increasing number of physicians in a wider variety of specialties are using US, ${ }^{3}$ and US training has become an important factor in medical students' preparedness for residency. The Association of American Medical Colleges' list of entrustable professional activities for entering residency includes "Recommend and interpret common diagnostic and screening tests," and its curriculum development guide specifically mentions US as the test of choice in a number of its sample clinical vignettes. ${ }^{4}$ To give its students the advantage of familiarity and expertise with this ever-expanding diagnostic modality, Touro University College of Osteopathic Medicine-CA (TUCOM) joined Ultrasound in Medical Education, California 
(UMeCali), a consortium of medical schools in California with a mission to introduce a longitudinal US education program tailored to address specific competencies. $^{5,6}$

Many medical schools, along with UMeCali, are developing US curricula to improve students' diagnostic and procedural skills. ${ }^{7}$ These schools need not develop their curricula from scratch; there are a number of published medical student US curricula that schools can use for guidance. ${ }^{7-9}$ There may be additional incentive for osteopathic medical schools to integrate US into their programs - preliminary data suggest that using US enhances students' palpatory skills and outcomes of osteopathic manipulative treatment. ${ }^{10,11}$

In 2011, TUCOM initiated the An Education in Osteopathic Ultrasound (AEIOU) program for all preclinical students (approximately 135 students per class). The program was designed with a staged approach, which is described in detail in the following section. To study the success of this course, we measured students' anatomical knowledge and diagnostic skills using postcourse surveys and formal assessment examinations, as well as overall Comprehensive Osteopathic Medical Licensing Examination-USA (COMLEX-USA) Level 1 scores and scores in the anatomy, diagnostic technology, and osteopathic principles and practice subdisciplines of COMLEX-USA Level 1. In this article, we also discuss the informal feedback we have received from our students and their clinical preceptors.

\section{Staged Approach}

A strategic, staged approach was developed at TUCOM for the implementation and expansion of US education in undergraduate medical education. The addition of US into the TUCOM curriculum was completed with oversight by a curriculum committee, which ensured that the gradual increase in exposure to US neither unnecessarily displaced other curricular components nor created an added burden to our students. The hours used for the study and practice of US were traded or incorporated into curricular hours dedicated to similar study (namely, anatomy and clinical skills). Figure 1 shows a detailed breakdown of the total hours per student spent on the US curriculum as it expanded over academic years.

This staged approach began in the 2011-2012 academic year, primarily as a complement and enhancement to the preclinical students' studies in anatomy. This first stage required only a single US machine and a skilled radiologist. These initial US sessions correlated directly with the first- and second-year anatomy curriculum; students used US on their peers to identify the same anatomical structures they had recently dissected in a cadaver. The anatomy being studied ranged from musculoskeletal structures to 4-chambered heart views to abdominal viscera.

The next stage included bringing US into some of the clinical skills laboratories. The initial clinical skills laboratory that used US was the laboratory on examination of the pregnant patient, which demonstrated fetal US techniques. In subsequent years, US education was incorporated into numerous other laboratories, including demonstration of ocular US during ophthalmic examination, cardiac and blood vessel US during cardiac examination, and abdominal US (including liver, gallbladder, and kidneys) during abdominal examination (Table 1). During this time, a single radiologist led these US sessions (totaling 5 curricular hours per student throughout the academic year).

The 2014-2015 academic year marked the planned expansion of our US curriculum from the preclinical into the clinical years. Small-group hands-on learning sessions were required for all students during their third-year callbacks. For students who wished to deepen their understanding of US, an expanded radiology rotation at TUCOM was offered as an elective. This rotation incorporated both basic point-of-care and advanced diagnostic US techniques, along with training in other radiologic modalities.

Gradual acquisition of equipment and facilities has accompanied and enabled the staged expansion. In the 2016-2017 academic year, the TUCOM Resource, 


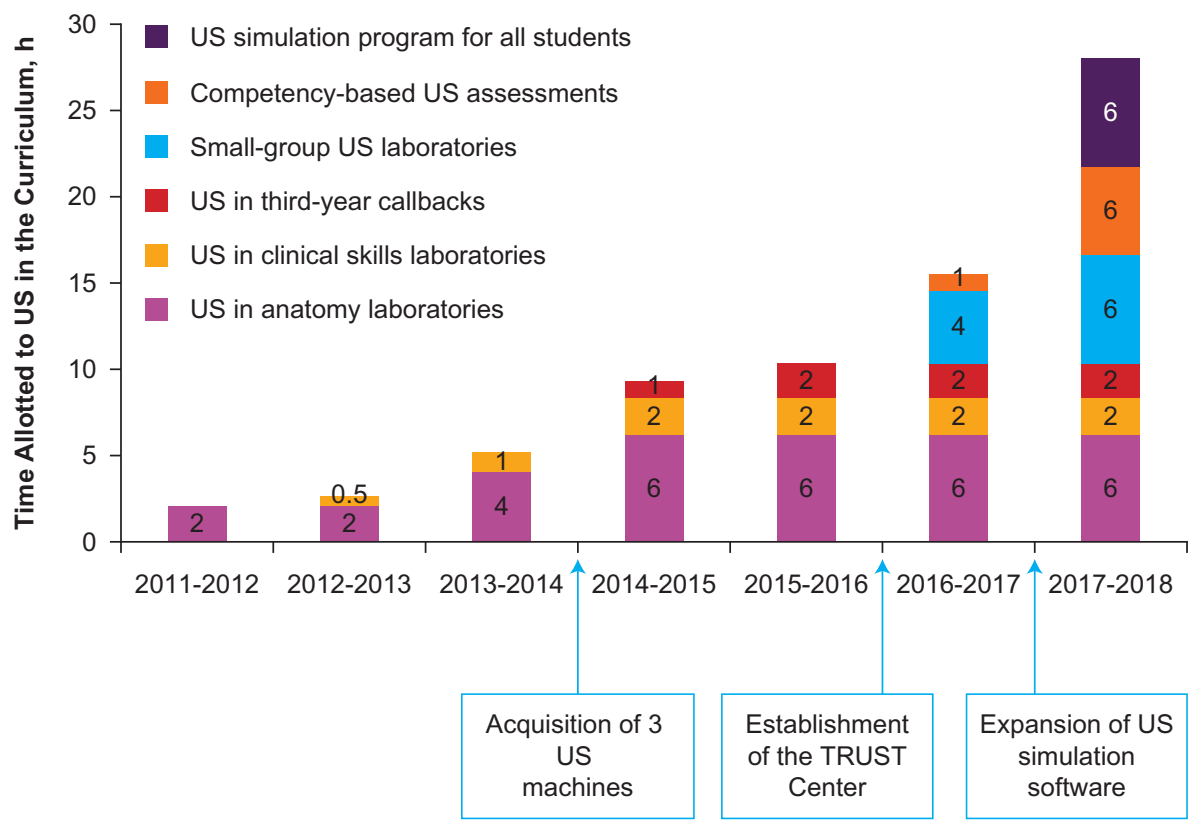

Figure 1.

Staged expansion of the Touro University College of Osteopathic Medicine-CA (TUCOM) ultrasonography (US) curriculum by academic year. Abbreviation: TRUST, TUCOM Resource, Ultrasound, and Training.

Ultrasound, and Training Center, a 5-room space designated specifically for US and simulation-based learning, was developed. This center provided an ideal practice, testing, and laboratory space for US. It enabled implementation of small-group US laboratories, which were the first sessions dedicated specifically

\begin{tabular}{lll}
$\begin{array}{l}\text { Table 1. } \\
\text { Clinical Skills-Based Ultrasonography Sessions } \\
\text { at Touro University College of Osteopathic } \\
\text { Medicine-CA }\end{array}$ \\
$\begin{array}{cll}\text { Semester } \\
\text { (Class Year) }\end{array}$ & Ultrasonography & Laboratory \\
\hline Spring (year 1) & $\begin{array}{l}\text { Cardiac and blood } \\
\text { vessel }\end{array}$ & $\begin{array}{l}\text { Cardiac } \\
\text { examination }\end{array}$ \\
\cline { 2 - 3 } & $\begin{array}{l}\text { Liver, gallbladder, and } \\
\text { kidneys }\end{array}$ & $\begin{array}{l}\text { Abdominal } \\
\text { examination }\end{array}$ \\
\hline Fall (year 2) & Ocular & $\begin{array}{l}\text { Ophthalmic } \\
\text { examination }\end{array}$ \\
\hline Spring (year 2) & Fetal & $\begin{array}{l}\text { Examination of } \\
\text { the pregnant } \\
\text { patient }\end{array}$ \\
\hline & & \\
\hline
\end{tabular}

and completely to US (Table 2). This also marked the first time that students were formally assessed on their competency with US. Students were required to demonstrate passable competence to perform a focused assessment with sonography for trauma. They attempted the assessment as many times as they needed (with assistance and practice before and

\section{Table 2.}

Small-Group Stand-Alone Ultrasonography Laboratories Associated With Competency-Based Assessments at Touro University College of Osteopathic Medicine-CA

\begin{tabular}{ll}
$\begin{array}{l}\text { Semester } \\
\text { (Class Year) }\end{array}$ & Laboratory \\
\hline Spring (year 1) & $\begin{array}{l}\text { Cardiac; vasculature } \\
\text { (aorta, IVC, DVT); renal; lung }\end{array}$ \\
\hline Fall (year 2) & Musculoskeletal \\
\hline Spring (year 2) & FAST examination \\
\hline
\end{tabular}

Abbreviations: DVT, deep venous thrombosis; FAST, focused assessment with sonography for trauma; IVC, inferior vena cava. 
between attempts) to demonstrate competency, and $100 \%$ of students passed this examination.

For the 2017-2018 academic year, we incorporated Sonosim US teaching software in all 4 years of the medical school curriculum. This software had previously only been used by students in the in-house radiology rotation or the radiology special interest group on campus.

\section{Continued Expansion}

The future of the US program includes plans for students in all 4 years to have their own handheld US machines. The college plans to continue expanding the scope of the education sessions, which soon will include procedural education for the clinical years so that invasive procedures can be learned in a clinically safe environment. Furthermore, TUCOM plans to continue expanding the competency-based skills assessments, so each year the college can demonstrate that all of its students meet the minimal level of competency with regard to indications for use, image acquisition, interpretation, and application to clinical decision making for various US studies. ${ }^{12,13}$

The impact of US in the TUCOM curriculum has been monitored closely to ensure that there were no unintended consequences. Students' scores on in-house assessments across all subjects, as well as on standardized examinations (shelf and board examinations), have remained consistent, if not higher, as highlighted in the Outcomes section. We have seen similar results in student feedback (formal and informal) regarding their impressions of the US curriculum and workload.

\section{Peer Educators}

As the TUCOM program expanded, the increase in available US machines, training modules, and assessments created a need for additional instructors. Some additional faculty were able to receive the necessary training and gain experience through US conferences and one-on-one sessions with TUCOM's US-trained expert; however, the need for additional instructors was primarily filled through the innovative peer-education program. This program allowed interested students to be trained as instructors for a particular education session.

Peer educators were recruited in a number of ways. One option was for third- or fourth-year students to do an elective radiology rotation with the faculty radiologist. The 2- or 4-week rotation resulted in a quick turnover of student educators, but being on a dedicated rotation allowed them substantial time to practice these skills, and students were able to become effective educators very early during their rotation, often in the first few days. Second-year students who had a keen interest in US were also offered the opportunity to be peer educators. These students attended practice sessions on their own time and had to balance this extracurricular learning with their standard curriculum. However, second-year students had the added benefit of being on campus the entire year, making them a stable part of the peer-educator system.

Using these 2 methods, TUCOM had between 4 and 10 peer educators at any given time. Thus, a low student-to-educator ratio of 1:8 was maintained without hiring any additional experts in US. Moreover, peer educators are able to offer one-on-one training to students who may be struggling with the US curriculum. The students have shown enthusiasm in both learning and teaching the US sessions, and the number of students who volunteer to be peer educators in US has continually exceeded our need.

Ultimately, the quality of the education is ensured by the founder of the program, a board-certified radiology professor (A.P.). He directly oversees the peer educators' training and supervises their instruction until he is confident in their abilities. It is estimated that it takes approximately 2 hours of faculty time to train a peer educator to an acceptable level for a particular learning session. These peer-educator training sessions are best done in group settings, thereby decreasing the total amount of faculty time needed. Once the peer educators are comfortable and competent, they can go on to train additional peer educators. 


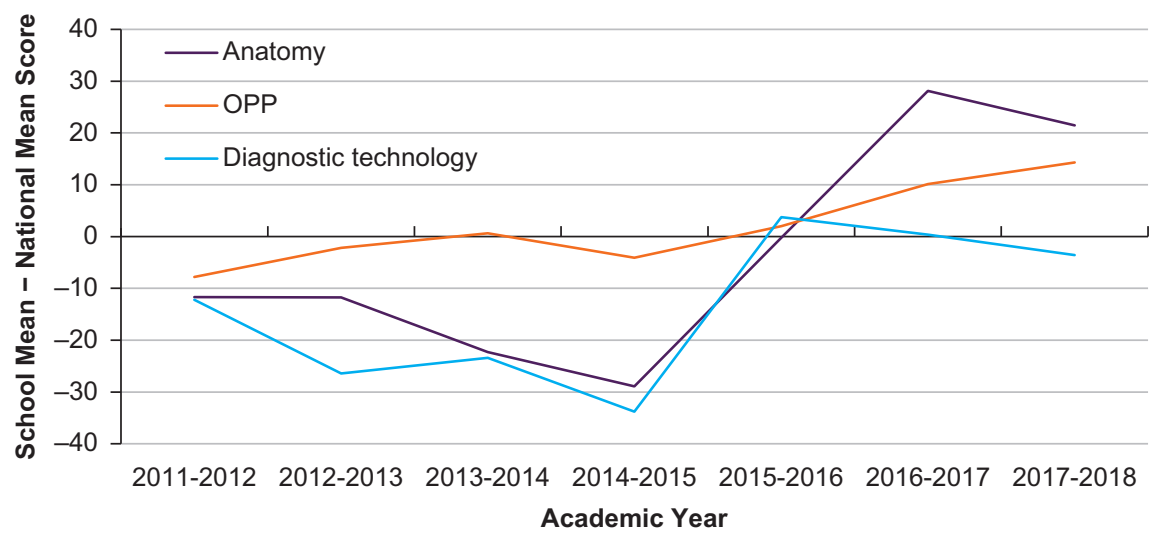

Figure 2.

Difference between school mean (Touro University College of Osteopathic Medicine-CA) and national mean scores on the Comprehensive Osteopathic Medical Licensing Examination-USA Level 1 for the subdisciplines of anatomy, osteopathic principles and practice, and diagnostic technology.

The use of peer educators enables TUCOM to efficiently manage costs by alleviating the need to hire multiple US-savvy professors and instead maximize the expertise of the radiology professor. An unanticipated benefit was the interest of other board-certified US technicians to train our students at core clinical sites. A cohort of these trainers has been impressed by TUCOM students' skills in US and has asked to participate in TUCOM's preclinical US laboratories. This addition of highly trained specialists is being planned, and student outcomes will be prospectively analyzed to compare them with those of the peer educator program.

\section{Outcomes}

As an indirect measure of success, we hypothesized that classes subjected to a more robust US curriculum would show an increase in COMLEX-USA Level 1 scores compared with previous years, specifically in the subject areas of anatomy, diagnostic technology, and osteopathic principles and practice. In our retrospective analysis, for the anatomy subdiscipline, the school mean went from 22.29 points below the national mean in 2013-2014 to 28.12 above it in 2016-2017. Similarly, the mean for the diagnostic technology subdiscipline increased by 20.44 points, moving from 23.4 points below the national mean to 0.38 points above it. The osteopathic principles and practice subdiscipline also improved (Figure 2).

Finally, we hypothesized that despite any potential increase in student workload from the US curriculum, students' ability to master the standard curriculum would not be diminished and overall COMLEX-USA Level 1 scores would not decrease. To ensure this outcome, the AEIOU program was integrated into the standard systems-based curriculum, minimizing the increase in workload and supplementing the standard curriculum. Our hypothesis was validated, as seen in Figure 3, which shows no substantial decrease in overall COMLEX-USA Level 1 scores relative to the national mean; on the contrary, an upward trend is shown.

Further evidence of the effectiveness of the curriculum was found in the formal assessment examinations. Owing to the first class-wide competency-based skills assessment that was instituted during the 2016-2017 academic year, $100 \%$ of the students in the classes of 2019 and 2020 met the minimum level of competency for the focused assessment with sonography for trauma.

A more subjective measure of the success of the curriculum is the soaring extracurricular interest in US that TUCOM has seen from its students. Since the inception 


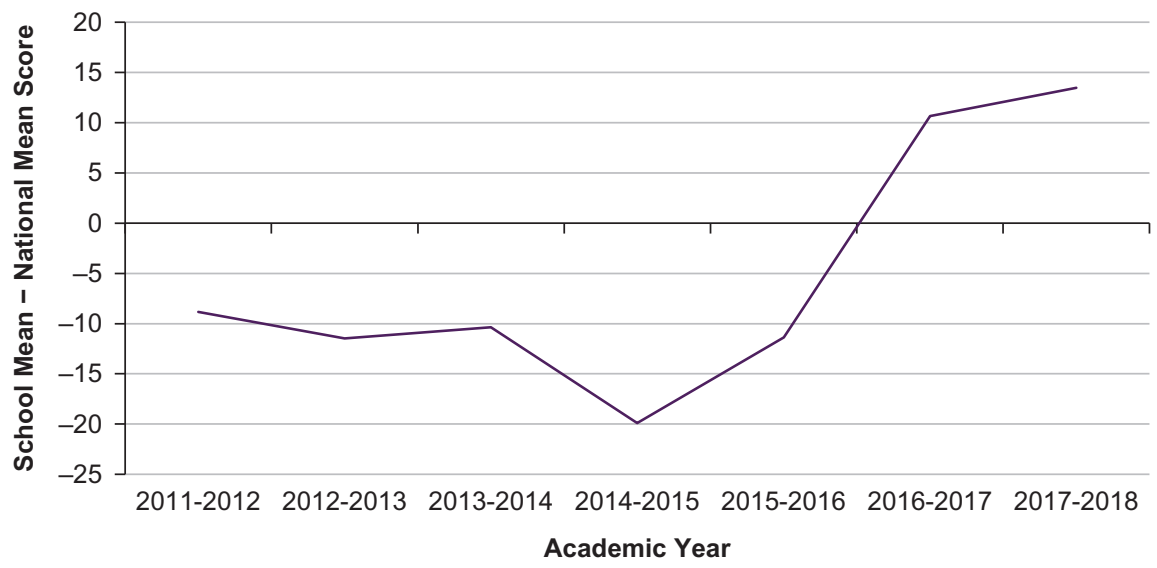

Figure 3.

Difference between school mean (Touro University College of Osteopathic Medicine-CA) and national mean scores on the Comprehensive Osteopathic Medical Licensing Examination-USA Level 1.

of the AEIOU program, there has been a progressive growth in student club use of US, particularly in the radiology, cardiology, and emergency medicine student interest groups. As students in these clubs have gained more practice and training with US, they have developed into advanced users and peer educators.

The increased comfort level and enthusiasm for US has led our students to seek out and participate in multiple US academic gatherings. These small-group hands-on experiences, such as the Ultrafest and SonoWars conferences, further teach medical students from multiple schools to use US as a fundamental clinical diagnostic tool at the hospital bedside and office settings. Over the years, TUCOM students have won awards in informal contests at these gatherings. This extracurricular involvement with US is encouraged, and TUCOM sees it and the students' performances at conferences as indirect measures of the curriculum's success.

\section{Discussion}

The implementation of the US curriculum at TUCOM has been steadily progressing through a staged approach, which allowed for immediate introduction of a curriculum in US with limited resources. The added experience, data, feedback, and outcomes from our pilot program provided the evidence needed to expand the program and attain the required funding and facilities. We believe this phased-in approach, or a variant of it, to be reproducible at any institution.

Although we consider the rise in COMLEX-USA Level 1 subdiscipline scores to be a promising trend, this metric has several limitations. First, COMLEXUSA subdisciplines have a large SD, so the benefit may be due to normal statistical variance. Furthermore, without a control group it is impossible to control for confounding factors. We believe that the value of US training is significant enough that to withhold such training from a subset of students for the sake of a control group would be unethical. Despite these limitations, the results show that TUCOM's US curriculum has not negatively affected students' overall COMLEX-USA Level 1 scores, while leaving open the possibility that there has been a direct benefit.

Further evidence of the benefits of the AEIOU program is primarily anecdotal but should not be discounted. Numerous students have displayed their US knowledge and skill on clinical rotations and reported positive reactions from preceptors. More notably, students have reported positive reactions from interviewers and program directors when applying for residencies. Further study is warranted to attempt to quantify the 
value and frequency of such experiences. We intend to develop a survey system to formally assess core preceptors' reactions to our students' US training, as well as to assess our students' impressions of the value of this training for their residency candidacies across various specialties.

Finally, the impact of TUCOM's US curriculum on students' knowledge and skill in osteopathic manipulation as well as osteopathic principles has been overwhelmingly positive, but again the evidence is primarily anecdotal. Many osteopathic manipulative medicine faculty believe that the frequent visualizations of diverse anatomical structures has aided students' ability to locate structures with osteopathic palpation. Considering the success of the program, TUCOM continues to search for new ways to integrate US into the osteopathic manipulative medicine curriculum and to assess the benefits.

\section{Conclusion}

It is clear that US will play an increasingly important role in numerous fields of medicine. With the AEIOU program at TUCOM, students will meet minimal competency thresholds and be able to perform and interpret crucial US studies. In addition, motivated students will have the foundations to become the pioneers of this evolving modality. These lessons also have the potential to enhance students' osteopathic palpatory skills as well as their radiologic and anatomical knowledge, which may be reflected in the upward trend of TUCOM students' COMLEX-USA Level 1 scores in those areas.

Based on this success, the AEIOU program will continue to be expanded and enhanced, and we will continue to investigate the measurable advantages of this curriculum. We hope that TUCOM can serve as a model for other institutions looking to develop a curriculum in US, and we believe TUCOM's staged approach is a realistic and replicable method. We look forward to having campus-wide competency and appreciation for US, and we are excited about the long-term benefits this program may have for students and their future patients.

\section{References}

1. Woo J. A short history of the development of ultrasound in obstetrics and gynecology. http://www.ob-ultrasound.net/history1.html. Accessed August 8, 2017.

2. Ultrasound. National Institute of Biomedical Imaging and Bioengineering website. https://www.nibib.nih.gov/science-education /science-topics/ultrasound. Accessed August 8, 2017.

3. Morris AE. Point-of-care ultrasound: seeing the future. Curr Probl Diagn Radiol. 2015;44(1):3-7. doi:10.1067/j.cpradiol.2014.05.012

4. Core Entrustable Professional Activities for Entering Residency: Curriculum Developers' Guide. Washington, DC: Association of American Medical Colleges; 2014. https://members.aamc.org/eweb /upload/Core\%20EPA\%20Curriculum\%20Dev\%20Guide.pdf. Accessed September 18, 2018.

5. Chiem A, Saucy Z, Dinh A, et al. Integration of ultrasound in undergraduate medical education at the California medical schools: a discussion of common challenges and strategies from the UMeCali experience. J Ultrasound Med. 2016;35(2):221-233. doi:10.7863 /ultra.15.05006

6. Clearfield M. A path to osteopathic distinction: the Touro California GROUPIE program [editorial]. J Am Osteopath Assoc. 2017;117 (8):488-494. doi:10.7556/jaoa.2017.09

7. Baltarowich $\mathrm{OH}, \mathrm{Di}$ Salvo DN, Scoutt LM, et al. National ultrasound curriculum for medical students. Ultrasound Q. 2014;30(1):13-19. doi:10.1097/RUQ.0000000000000066

8. Dinh VA, Lakoff D, Hess J, et al. Medical student core clinical ultrasound milestones: a consensus among directors in the United States. J Ultrasound Med. 2016;35(2):421-434. doi:10.7863 /ultra.15.07080

9. Hoppmann RA, Rao VV, Bell F, et al. The evolution of an integrated ultrasound curriculum (iUSC) for medical students: 9-year experience. Crit Ultrasound J. 2015;7(1):18. doi:10.1186/s13089-015-0035-3

10. Shaw K, Dougherty J, Treffer K, Glaros A. Establishing the content validity of palpatory examination for the assessment of lumbar spine using ultrasonography: a pilot study [published correction appears in J Am Osteopath Assoc. 2013;113(6):449]. J Am Osteopath Assoc. 2012;112(12):775-782.

11. Kondrashova T, Lockwood M. Innovative approach to teaching osteopathic manipulative medicine: the integration of ultrasonography. J Am Osteopath Assoc. 2015;115(4):212-220. doi:10.7556 /jaoa.2015.043

12. Cawthorn TR, Nickel C, O'Reilly M, et al. Development and evaluation of methodologies for teaching focused cardiac ultrasound skills to medical students. J Am Soc Echocardiogr. 2014;27(3):302-309. doi:10.1016/j.echo.2013.12.006

13. Mulvagh SS, Bhagra A, Nelson B, Narula J. Handheld ultrasound devices and training conundrum: how to get to "seeing is believing." J Am Soc Echocardiogr. 2014;27(3):310-313. doi:10.1016 /j.echo.2014.01.011

๑) 2018 American Osteopathic Association 